\title{
Assessment of Radioactivity Dispersion Model for Surface Water
}

\author{
Ahmet Erdal Osmanlioglu ${ }^{1 *}$
}

${ }^{1}$ Istanbul University - Cerrahpasa, Istanbul, TURKEY

*Corresponding Author: email@affiliation.com

Citation: Osmanlioglu, A. E. (2022). Assessment of Radioactivity Dispersion Model for Surface Water. European Journal of Sustainable Development Research, 6(1), em0175. https://doi.org/10.21601/ejosdr/11398

\section{ARTICLE INFO}

Received: 28 Mar. 2021

Accepted: 22 Oct. 2021

\begin{abstract}
Uranium is an element commonly found in natural groundwater can be measured up to 100-500 $\mu$ g per L without impact from mining. Determination of radionuclide concentrations by dispersion in the surface water is based on several mathematical models. In this paper, the main purpose of this research is to estimate the distribution of radionuclide contamination in the water body under laboratory conditions. The simplest approach in deriving radioactivity dispersion was evaluated by a laboratory-scale glass tank $(60 \times 60 \times 60 \mathrm{~cm})$ which was used for dispersion measurements in the laboratory. The box model transition test has taken into account several parameters; these are mixing ratio, transit time and decay to predict radionuclide concentrations in the water at the location of interest. Radioactive solution $(650 \mathrm{~Bq} / \mathrm{liter})$ was released in the box and samples were taken from $10 \mathrm{~cm}$ intervals every 5 minutes. Results show that radioactivity dispersion can be predicted briefly by using this model for surface waters. Laboratory water tank measurements show that radioactivity dispersion of uraniumbearing solution in surface water compatible with the equation. Measured transition time in the field is the most valuable information that improves the ability to predict the transport and dispersion in surface water.
\end{abstract}

Keywords: uranium, radioactivity, dispersion, water

\section{INTRODUCTION}

In the nature, the primary ore mineral of uranium is uraninite $\left(\mathrm{UO}_{2}\right)$. Many other secondary minerals available in nature include carbonates, sulfates, phosphates, silicates, and multiple oxides. Uranium concentrations in nature are dependent on types of rock formations. In igneous rocks, uranium concentrations are lower in dunites and peridotites (0.1 - $0.5 \mathrm{ppm}$ ) when compared to granites and monazites (up to $20 \mathrm{ppm}$ ). In sedimentary rocks, likely depend on the formation such as lower in limestones and dolomites (0.1 - 2 ppm) when compared to shales (up to $25 \mathrm{ppm}$ ) in Turkey. In metamorphic rocks, uranium concentrations were found the lowest in marble (up to $0.25 \mathrm{ppm}$ ) when compared to gneiss (up to $15 \mathrm{ppm}$ ). Although 15 isotopes of uranium are available starting from U-227 to U-240, only three uranium isotopes are found in nature (Table 1). U-234, U-235 and U-238 uranium isotopes occur naturally and U-235 and U-238 are parents of series that end in lead isotopes. The common oxidization states of uranium are U (III), U (IV), U (V) and U (VI). The U (IV) state of uranium is stable in water if $\mathrm{pH}$ is lower than 2.5.

Water is the principal pathway for dispersion of uranium contamination from mining or milling operations. Radioactively contaminated water may generate because of surface water runoff from and seepage through uranium bearing waste rock piles and uranium ore stockpiles. The radioactivity of this water is generally derived from natural radioactive isotopes either dissolved or attached to suspended particles by which contamination WHO (World Health Organization) has made the recommendation for drinking water limit as $15 \mu \mathrm{g}$ per litre. The radioactivity comes from naturally occurring radioactive material or from an anthropogenic source. The source of radiation exposure in general (ICRP, 2007), and of the effects of radioactive material present in drinking water may have on humans have been widely investigated (EC European Union Council Directive, 1998; UNSCEAR, 2000). Dispersion data has been used in the formulation of water quality guidelines identifying the permissible concentration of radioactivity, and activity concentrations of several radionuclides in water. It is based on the chemical toxicity of uranium. Terrestrial radionuclides, which is generated from earth, crust also directly impact on the water cycle and become available in discharged waters used by humans. Natural radioactivity, which is generated from natural sources in mining and mineral processing facilities monitored from various ores, covers uranium and thorium (U, $\mathrm{Th}$ ), differs from nuclear and radioactive waste that generated at nuclear power plants and other industrial operations. Waste from mining and milling activities contains only low concentrations of radioactive material but it is generated in large volumes in comparison with waste from other facilities. Implementation of the waste management methods at these source facilities are therefore different and usually involve 
Table 1. Natural uranium isotopes

\begin{tabular}{ccc}
\hline Natural Isotopes & Abundance (\%) & Half Life (year) \\
\hline $\mathrm{U}-234$ & 0.0056 & $2.48 \times 10^{5}$ \\
\hline $\mathrm{U}-235$ & 0.72 & $7.13 \times 10^{8}$ \\
\hline $\mathrm{U}-238$ & 99.72 & $4.51 \times 10^{9}$ \\
\hline
\end{tabular}

waste disposal or near the surface, in the on-site of the mine and/or mill sites. In addition, the radioactive waste contains long-lived radionuclides, and this has important impacts for its management because of the requirement of control for the long time periods (IAEA, 2002) therefore, the element uranium has become an important issue in water. Radionuclides, which is generated from natural uranium bearing rocks found in the environment, can be dissolved into water, which is a long-term source of radionuclides for the freshwater ecosystems (Jobson, 1997). Comprehensive literature is available to assess radionuclide transport models that are applicable to surface waters. These models begin with a one-dimensional channel model or a box-type model and developed through to the two and three-dimensional models. These proposed models describe the main characteristics of radioactivity dispersion; including the mechanisms governing radionuclide-sediment interactions. The first models have annually averaged box models in which ionic exchanges were analysed by the main parameter of distribution coefficient $(\mathrm{Kd})$. In these models, dispersion of a specific radionuclide was simulated with the predictions of the model based on observations (Howorth et al., 1988; Kershaw et al., 1998). They have their own applicability limits and suitability for different types of water bodies. Such as rivers, estuaries, coastal waters, lakes, seas, and impoundments. In this research box type model was used to simulate water body. Most of these models were reviewed in case of adaptability for a simple generic model. Developing an appropriate kinetic model in the presence of of oxygenated compounds have been studied in laboratory scale (Barghi et al., 2012). The Kd distribution coefficients for radionuclides depend on the physical and chemical features of the variability and radionuclide transport models are generally based on the advection/diffusion equation. Some of will be effective to determine radionuclide transport mechanism (Abril and Fraga, 1996). These are;

- Advection and dispersion tendency of radionuclides

- Current, surface waves and turbulent mixing

- Radionuclide decay

- Radionuclide sources and locations

- Radioactivity of each radionuclide

- The interaction between radionuclides and sediment

In this research, radionuclide sources and locations were effective parameters. This study provides an innovative model for predicting the distribution mechanisms of radionuclides in natural water systems under laboratory conditions. Prediction of transportation for dissolved radionuclides in clear surface waters is relatively simple because of low sediment concentrations and small distribution coefficient $(\mathrm{Kd})$ values. However, in case of availability of higher sediment concentrations radionuclide adsorption/desorption mechanism should be taken into account.
In this case, first, the radionuclide adsorption mechanism with reaction kinetics with sediments should be determined for the generation of $\mathrm{Kd}$ data that can be used in the model. For this reason, in order to assess radioactivity dispersion models following parameters should be taken into account in the transport mechanisms:

- Advection and dispersion of radionuclides by water movements

- Radionuclide decay

- The interaction between sediment and radionuclides (adsorption, desorption, deposition)

- Radionuclide release locations

- Radionuclide water mixing properties

\section{MATERIALS AND METHODS}

In water environments, uranyl ions can be found in various forms, which includes many complexes with anions such as sulfate, carbonate, and fluoride. In the geological environment related to radioactivity dispersion, $\mathrm{U}$ (IV) and $\mathrm{U}$ (VI) are the most important oxidation states. $\mathrm{U}(\mathrm{VI})$ is effective in oxidizing environments and $\mathrm{UO}_{2}(\mathrm{OH})_{2}$ and $\mathrm{UO}_{2}\left(\mathrm{CO}_{3}\right)_{3}$ are predominant solutions from $\mathrm{pH}$ 8. In seas, because of high chlorine environment, $\mathrm{UO}_{2} \mathrm{Cl}$ is predominant at $\mathrm{pH}$ below 6 .

The mining of uranium ores produced huge amounts of waste. These are; excavated topsoil, overburden rock, uranium-bearing waste rock and sub economical grade ores (it is called as protore). The protore contains significant amounts of uranium and generally stockpiled on site for further processing. These files generate contaminated surface water.

Radiological characteristics of surface water cause health effects and these health impacts are effective via various emissions generated by the site in two ways. These are;

- The water qualities of surface and groundwater can have an impact on human health via ingestion and or through irrigation of agricultural land or watering livestock.

- The air quality around the site emission of contaminated dust or radon emanation will potentially have a direct effect on human activities and health via inhalation.

For this reason, spectrometric surveying of radiation, which covers gamma, alpha and beta, is needed to determine the radiological characteristics. Modelling of the dispersion through waters is an important method for the assessment and controlling of potential impacts of these contaminated waters (NEA, 2002). Uranium liquid was taken from surface waters of tailings/outcrops of high concentrated uranium-bearing formations.

Three types of models in surface waters can do prediction of radionuclide transport. 


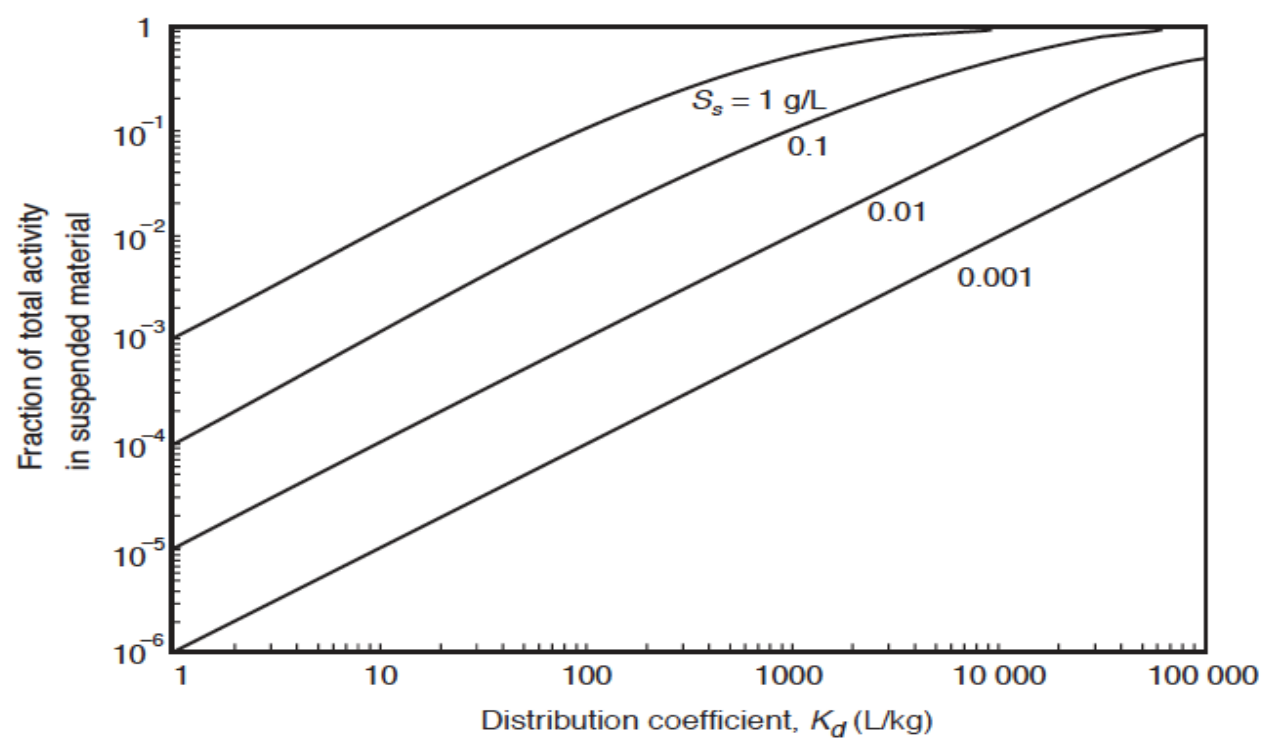

Figure 1. Suspended sediment concentrations versus distribution coefficients (IAEA, 2001)

1. Numerical models; describe radionuclide dispersion into finite difference or finite element forms by using basic equations

2. Box type models; homogeneous compartments are used in this model to describe the entire water body or sections of a water body

Both of these models include sediment-radionuclide interactions.

3. Analytical models solve the basic radionuclide transport equations.

Generally, simplifying assumptions are made in these model calculations depending on the water body geometry, water flow conditions, and dispersion mechanisms in order to get analytical solutions to the governing equations.

Various amount of sediments exists in surface waters. Interaction of sediment with radionuclides, which are dissolved in water, the concentration of the radionuclides in the dissolved phase, is decreased because of radionuclide adsorption on to sediment particles. Result of this mechanism, the concentration of radionuclides on the suspended sediment and bed of the water body will be increased because of the adsorption and particle precipitation. Relation between the suspended sediment concentrations on the radionuclide concentration are shown in Figure 1.

The distribution coefficient $\mathrm{Kd}(\mathrm{L} / \mathrm{kg})$ is used to describe the exchange of radionuclides between the Dissolved and sediment sorbed phases. It is defined for a given radionuclide as the following equation;

$$
K_{d}=\frac{C_{S S}}{C_{d r}}
$$

$C_{S S}$ : Radionuclide concentration, which is sorbed by sediments per unit weight of sediment $(\mathrm{Bq} / \mathrm{kg})$

$C_{d r}$ : Radionuclide concentration, which is dissolved per unit volume of water $(\mathrm{Bq} / \mathrm{L})$

Studies were performed to evaluate the redistribution of uranium-series radioactivity in the surface water. The simplest approach in deriving radionuclide concentrations in river water is based on a generally applicable model. The model uses only the mixing ratio, transit time and decay to predict radionuclide concentrations in the water at the location of interest is given by the equation:

$$
C_{w, i}=P\left(\frac{Q_{i}}{F}\right) M_{p} \exp \left(-\lambda_{i} t_{p}\right)
$$

where,

$C_{w, i}:$ Concentration of radionuclide $i$ in water (Bq/liter)

$P \quad$ : Conversion factor to relate units used for release rate and river flow to units of concentration in water.

$Q_{i} \quad$ : Input rate of radionuclide $i$ into the river (Bq/liter)

$F \quad:$ Effluent flow (m³/year)

$M_{p}$ : Mixing ratio, a dimensionless reciprocal of the dilution factor

$\lambda_{i} \quad$ : Radioactive decay constant of radionuclide $\left(\mathrm{s}^{-1}\right)$

$t_{p}$ : Average transit time for radionuclides to reach the location of interest (s)

In this paper, the simplest approach in deriving radioactivity dispersion is evaluated by laboratory tests. The model uses only the mixing ratio, transit time and decay to predict radionuclide concentrations in the water at the location of interest. A laboratory scale glass tank $(60 \times 60 \times 60$ $\mathrm{cm}$ ) was used for dispersion measurements in the laboratory (Figure 2). Radioactive solution (650 Bq/liter) was released at point $A$ and samples were taken from $10 \mathrm{~cm}$ intervals from point $A$ to point $\mathrm{G}$ after every 5 minutes. Effluent flow and mixing ratio were assumed as constant parameters. Samples were taken from different sampling points in three duration periods like 5, 10 and 20 minutes. Measurements were taken by using gamma-ray spectrometry. In this research, spectrometry system was used which is consisted of a high purity germanium coaxial (GCD-80-210) detector with \%80 efficiency. The system is integrated with a multi spectrum hybrid converter (MCA), high voltage $(5000 \mathrm{~V})$ with negative polarity. Energy resolutions at $122 \mathrm{keV}$ and $1.33 \mathrm{MeV}$ are 1000 $\mathrm{eV}$ and 2.10 respectively. The full width at half maximum (FWHM) is an expression of the extent of a function given by 


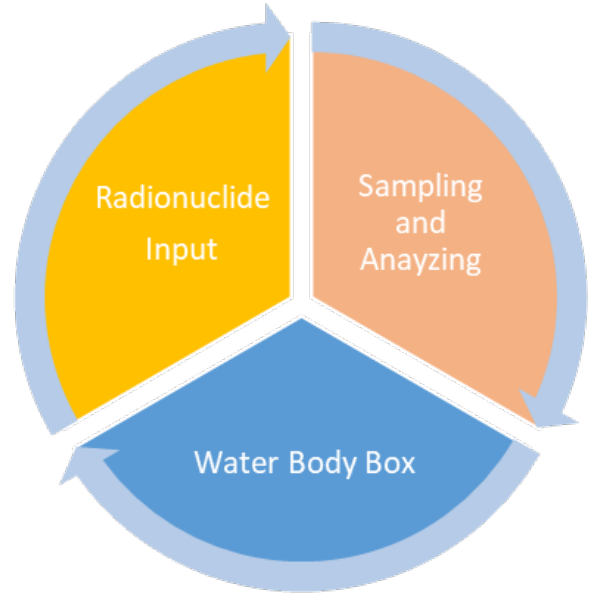

Figure 2. Closed circuit test process

the difference between the two extreme values of the independent variable at which the dependent variable is equal to half of its maximum value. Peak/Compton ratio is 77:1, Peak shapes FWHM values were arranged as 2 and 3 respectively for FW1M and FW02M. Energy range is between $40 \mathrm{keV}-10 \mathrm{MeV}$ (GCD). The detector was mounted on a vertically connected to the Polycold PCC-70K cooling system. The position of the crystal within the shield was connected at the bottom of the counting chamber. A high-purity copper end cap was used for enclosing of the crystal and its preamplifier. LSRM Spectra Line GP software was used to record the intensity of the incident and transmitted gamma rays. It has been developed for spectrometric measurements and precision processing of gamma-spectra and supports all service and functional capabilities of the LSRM software package.

\section{RESULTS AND DISCUSSION}

The following effective factors were evaluated in deriving effluent concentration limits according to prescribed dispersion conditions:

Nature of the effluent (Acid mine drainage, runoff from piles, from tailings)

The concentration of contaminants (radionuclides, discharged total activity)

Effluent Flow rate

Dilution factor (Background concentration)

Seasonal changes (Radionuclide concentration by leaching)

Water quality standard

Treatment of contaminated water is usually mandatory. National regulations set effluent release criteria. Although most of them based on ICRP recommendations, the maximum allowable concentration limits for each contaminant differs from country to country. Some countries have defined specific radionuclide concentration or activity limits for surface water discharge. Generally, drinking water quality standards are applied to discharge mine water as maximum allowable release limits. Such as for uranium contamination limits in water is determined between $0.1,0.5$ and $1.8 \mathrm{mg}$ per liter for Czech

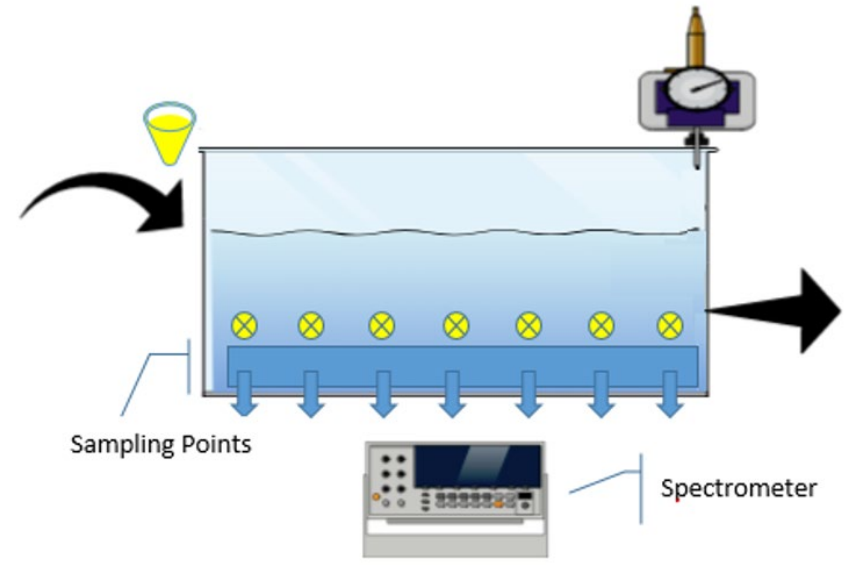

Figure 3. Water dispersion box

Rep., Germany, and France respectively. In addition, interactions between groundwater and surface water bodies (recharge and discharge zones) provide one of the major pathways through which groundwater contaminants interact with humans and the wider terrestrial environment (IAEA, 1999).

Spectrometric analysis results were evaluated for each checkpoint according to time and distance. As a result, radioactivity concentration of uranium-bearing solution decreased depending on the distance from the release point of the source as shown in Figure 3.

Data from the test results were checked with the generic equations and validated by automated verification and validation software. By using this validation software, the tests based on the specification were generated and compared the behaviour of the specification and a running implementation.

\section{CONCLUSIONS}

Spectrometric analysis results show that radionuclide distribution profile can be obtained according to time and distance. Distribution of any radionuclide can be predicted by using this approach. This study reviews radionuclide dispersion models and presents a basic empirical equation for radioactivity dispersion. This modelling approach provides reasonable predictions in situations where adequate field data are not available. Mathematical relations are given for the radionuclide concentration in water, effluent flow, and mixing ratio, decay constant of interested radionuclide as a contaminant and the duration of the time for radionuclides to reach the location of interest. All the relations needed to predict the transport and dispersion of radionuclides define the relation of concentration. Laboratory water tank measurements show that radioactivity dispersion of uraniumbearing solution in a surface water compatible with the equation. Transition time for uranium radionuclides to reach the sampling point shows that the dispersion mechanism of the radioactivity directly related to time after release in surface water. In the case of field data availability, transit time is the most valuable information that can be collected to improve the ability to predict the transport and dispersion in surface water. Therefore, monitoring of surface water has vital importance for site-specific dispersion model generation and risk 
assessment. Because of the increased awareness of environmental issues and impacts on the public health caused by radioactivity, many countries in the process of adopting their regulations aimed at improving and reinforcing the environmental protection against radioactive contamination.

Funding: No external funding is received for this article.

Declaration of interest: The author declares no competing interests.

Ethics approval and consent to participate: Not applicable.

Availability of data and materials: All data generated or analyzed during this study are available for sharing when appropriate request is directed to the author.

\section{REFERENCES}

Abril, J. M. and Fraga, E. (1996). Some physical and chemical features of the variability of kd distribution coefficients for radionuclides. Journal of Environmental Radioactivity, 30(3), 253-270. https://doi.org/10.1016/0265-931X(95)00010-8

Barghi, B., Fattahi, M. and Khorasheh, F. (2012). Kinetic modeling of propane dehydrogenation over an industrial catalyst in the presence of oxygenated compounds. Reaction Kinetics, Mechanisms and Catalysis, 107, 141-155. https://doi.org/10.1007/s11144-012-0455-z

EC European Union Council Directive (1998). 98/83/EC The quality of water intended for human consumption. Official Journal of the European Communities, L330/32, 5.12.98.

Howorth, J. M. and Eggleton, A. E. J. (1988). Desmet G (ed) Modelling the sea to land transfer of marine discharges from Sellafield. Validation against environmental measurements. In Reliability of radioactive transfer models (pp. 261-267). Elsevier. https://doi.org/10.1007/978-94009-1369-1_30
IAEA. (1999). Technical options for the remediation of contaminated groundwater. International Atomic Energy Agency. IAEA-TECDOC-1088, Vienna.

IAEA. (2001). Generic models for use in assessing the impact of discharges of radioactive substances to the environment. International Atomic Energy Agency. Safety Report Series No 19, Vienna.

IAEA. (2002). Management of radioactive waste from the mining and milling of ores. International Atomic Energy Agency Safety Standards Series No. WS-G-1.2, STI/PUB/1134:3642

ICRP. (2007) Recommendations of the International Commission on Radiological Protection. ICRP Publication 103, ICRP-37: 2-4.

Jobson, H. E. (1997). Predicting travel time and dispersion in rivers and streams. Journal of Hydraulic Engineering, 123(11), 971-978. https://doi.org/10.1061/(ASCE)07339429(1997)123:11(971)

Kershaw, P. J., Pentreath, R. J., Gurbutt, P. A., Woodhead, D. S., Durance, J. A. and Camplin, W. C. (1988). Modelling the behaviour of long-lived radionuclides in the Irish Sea. Comparison of model predictions with field observations. In G. Desmet (Ed.), Reliability of Radioactive Transfer Models (pp. 241-249). Elsevier. https://doi.org/10.1007/978-94009-1369-1_28

NEA. (2002) Environmental remediation of uranium production facilities (pp. 26-33). Nuclear Energy Agency, OECD.

UNSCEAR. (2000). Sources and effects of ionizing radiation. United Nations Scientific Committee on the Effects of Atomic Radiation. ANNEX B Exposures of the public and workers from various sources of radiation United Nations, New York. 